\title{
Choosing the Right Medium for Municipal eParticipation Based on Stakeholder Expectations
}

\author{
Marius Rohde Johannessen, Leif Skiftenes Flak, and Øystein Sæbø \\ University of Agder, Department of Information Systems \\ Service Box 422, 4604 Kristiansand, Norway
}

\begin{abstract}
This paper examines the expectations and communication needs of relevant stakeholder groups for municipal eParticipation in a small Norwegian municipality. We identified relevant stakeholder groups with the municipality, and asked them about their communication preferences through a combined Delphi study and survey approach. The findings show that information about local issues, information about issues relevant for the individual stakeholder, and dialogue on business' needs and employment are the three most important communication needs. E-mail and the municipal web site are the two preferred modes of communication, with social media ranking third. For dialogue and participation, a face to face meeting is the preferred mode of communication. Our findings show that effective municipal communication requires a number of different media, depending on what is being communicated. We conclude by outlining a framework for media choice in eParticipation.
\end{abstract}

Keywords: eParticipation, stakeholder theory, social media, media choice.

\section{Introduction}

Digital media are increasingly used by governments and political parties in their communication with citizens, business and organisations. It has been claimed that digital media "are set to transform political structures and organisations, political campaigning, lobbying strategies and voting patterns" [1]. In Norway, the vision for digital communication is to be among the best in the world on digital citizen dialogue, digital services and efficient eGovernment [2]. Politics as a field is becoming more and more dependent on good media and communication skills [3], but information overload and filtering problems presents government with massive challenges related to media choice [4], and there is often a gap between government choice and citizen expectations [5].

Deliberation in various digital media can increase the political sophistication of citizens [6], and online participation extends the political centre by including more citizens, but may also increase the distance between the ones in the centre and those in the periphery [7], widening the gap between those who are "inside" and "outside" of the public debate. Participants in political deliberation initiatives are rarely representative of the general population, but organising deliberation programs in different settings such as online surveys and discussions, face to face meetings or informal dinners could include citizens with more diverse backgrounds [8]. The fact that today's government is technocratic and relies ever more on expert reports and 
opinion further alienates the average citizen, who feels s/he has nothing to contribute to a debate where the focus is on consultancy reports and numbers [9].

To include more citizens in the decision making process, governments have attempted to implement various participatory techniques, but these are often biased towards the socio-cultural background of government officials, and leaves little space for the actual needs of citizens [9]. Thus, our first aim is to discover what various citizen groups actually want to talk to government about, and through which medium they prefer to communicate. We have focused on the municipal level, as this is where the diversity of citizen interaction is largest in Norwegian government.

While political parties have embraced technology, they are yet to embrace the social concepts underlying the technology [10]. A recent study defines both the social and technical concepts of technology for research, and calls for practical applications of the theoretical framework [11]. This leads us to our second objective, which is to aid practitioners in government who are uncertain about which medium they should use for various eParticipation efforts. Thus, our research questions for this study are:

1: Who are the stakeholders in eParticipation at the municipal level?

2: What are their communication needs and media preferences?

3: How can practitioners choose media for various types of communication?

To answer these questions, we conducted a Delphi study of the various citizen stakeholder groups, and distributed a survey to capture the opinions of stakeholders who did not want to take part in the Delphi study. Finally, based on the findings from the Delphi study and survey we applied the theoretical framework of Johannessen and Munkvold [11], and synthesised several existing frameworks for technology choice and communication to create a tool that could help practitioners in government in choosing the right technologies for different communication needs.

\section{Theoretical Premises: Technology Evaluation through Genres}

While our study identifies citizen preferences for eParticipation, there is still the need to transfer this knowledge to governments' technological choice so that government can decide which tools to use for which purpose. Existing literature has several examples of this, but mostly focuses on either communication or technology. A synthesis between these studies could lead us towards a more holistic solution.

The eParticipation tool assessment [12] combines the analysis of technical functionality with several other factors such as the level of participation it can address and the stages in the decision making process that are supported. Existing frameworks address the technological requirements of eParticipation well, but it is made from the perspective of government, and does not take into account the varying needs of different citizen groups, or the socio-technical nature of technology. However, to succeed, it is important to take citizens' needs into account [13], and to address technology from a socio-technical perspective [11].

To extend the framework to include the socio-technical perspective so it can more easily be used to identify the communication needs of citizens, we used elements from genre theory. A genre is defined as "a typified communicative action which is invoked in response to a recurring situation" [14]. Genres that are routinely enacted, 
such as questions to politicians, reports on potholes or specific types of input to the decision making process can be seen as a genre repertoire [15] of eParticipation. Genres are identified through similar form and function [14], as well as technical functionality [16], and can be analysed through the 5W1H framework, where you ask Why are we communicating, What is the content, Who are the participants, Where should the communication take place, When and How should we communicate. The framework helps uncover how and when the genre is enacted, in what situations it is used, who the participants are and why the genre is used [17]. Genre theory has been used in several previous studies of eParticipation [18-21].

There are some examples of genre based methods for systems planning and development in government. Päivärinta et.al. [22] present a method for Information Systems Planning based on genre theory, where the communication genres are the deciding factor for the technological choice. The framework includes a stakeholder analysis of who the producer and the user of the information is, as well as genre and metadata analyses. Others have built upon this framework to create a method for development of eGovernment portals, where the genre perspective is extended through the inclusion of life-events in the planning stage [23]. In another example, genre theory have been used to help structure and plan discussion forums for local eParticipation through the 5W1H method [18].

While both the assessment tools and the genre approaches are good, none of them address both the technological and communicative aspects of eParticipation. Combining the two into a genre and technological choice framework could aid practitioners in choosing the appropriate media for different eParticipation activities. In section five, we begin to sketch the outlines of such a framework, which combines the genre and technology analyses referenced in this section.

\section{$3 \quad$ Research Method}

The findings reported in this paper are part of an on-going collaboration between the university and a municipality in southern Norway. The municipality has 8000 inhabitants, and relies heavily on agriculture. Three large fjords have led to a scattered population, with about half of the inhabitants living in the centre, and the rest spread out across the municipality.

As our objective was both to identify stakeholder groups and their preferences, we chose multiple research methods. By a multiple approach different aspects of reality may be explored to gain richer understanding of the research topics investigated [24]. Our first objective was to identify relevant stakeholder groups through a stakeholder analysis. Stakeholder theory was originally a set of tools and methods to identify relevant stakeholders [25], and stakeholder theory has been adapted to the eGovernment field [26, 27]. Our stakeholder analysis was conducted in collaboration with politicians and government officials in the municipality, and we came up with a total of 23 local stakeholder groups. Stakeholders with similar characteristics were then grouped into 10 panels for the Delphi study, which provided us with a list of stakeholders from politics, government administration and civil society.

Data collection took place between April and November 2011. We collected our data using the Delphi method [28, 29]. The Delphi method is well suited for studies 
where "judgmental information is indispensable", and has been used for concept and framework development in Information Systems studies [28] and public policy development [30]. The method consists of three phases: Brainstorming of issues, consolidation, where the list is narrowed down, and finally the ranking phase, where the participants attempt to reach consensus on which of the identified issues are most important $[28,29]$. The respondents were asked to provide a qualitative answer to the question what do you want to communicate with government about, and which media would you prefer to use? In addition, there was a short text explaining the purpose of the study.

The municipality recruited participants based on our stakeholder analysis, and these were invited to take part in the Delphi survey. The survey was distributed to 80 participants, of which 22 chose to participate. In addition to this, we distributed a regular survey to the municipality's inhabitants, which resulted in 36 additional respondents.

We were not able to reach consensus, as the participants lost interest in the study after the first round of ranking. This is a common problem with the Delphi method, but fortunately the amount of data from initial rounds is often rich enough that we can draw some conclusions, as shown by Päivärinta \& Dertz [31]. In our case, both the brainstorming and first ranking phases provided insights into the communication preferences for the different stakeholder groups, as well as their preferred communication technologies for each form of communication.

The brainstorming phase identified 31 different communication categories, which were narrowed down to ten in the consolidation phase. Eight of these were ranked by more than 50 per cent of the participants, and thus considered to be at least moderately important for a majority of the respondents. The survey data confirmed these as the most important issues. Finally, we asked the respondents to report which communication technology they preferred for each of the communication categories, and found that more than 70 per cent prefer some form of digital communication.

Treating the communication categories as genres of communication [14], we combined the technological framework of Tambouris et. al. [12] and the genre based frameworks $[18,22,23]$ to create an overview of which technologies are suited to which communication genre.

\section{$4 \quad$ Results}

\subsection{Who Are the Stakeholders?}

Stakeholder groups were identified in collaboration with representatives from the municipality. The objective was to include every government and civil society group that has a need to communicate with the municipality.

In eGovernment we usually discuss three main stakeholder groups: Politicians, administration and the civil society [32]. For the municipality, it was important to solicit opinions from these as separate stakeholders. The relation between politicians and the administration was mentioned as very important, due to the different responsibilities of these groups.

Defining civil society stakeholder groups is more difficult, as they can be divided in several ways, such as age, education, ethnicity, business owners and associations. 
We attempted to include as many groups as possible, and came up with eight civil society stakeholders: Business, Service users, associations, expats, immigrants, youth, senior citizens and finally a group for the "silent majority" of citizens with no organizational membership. The identified stakeholder groups are listed in Table 1.

Table 1. Municipal stakeholder groups

\begin{tabular}{|c|c|c|}
\hline Sphere & & Stakeholder groups \\
\hline Political & & Municipal executive board \\
\hline Government & & Administration officials from city hall \\
\hline Administration & & Municipal employees from health and education \\
\hline \multirow[t]{8}{*}{ Civil Society } & Business & Business association, Tourism, Primary industry \\
\hline & \multirow{7}{*}{$\begin{array}{l}\text { Organizations/ } \\
\text { citizen groups }\end{array}$} & Service users: PTA, Health care patients \\
\hline & & Associations: Residents, religious groups, sports \\
\hline & & Expats \\
\hline & & Immigrants and new residents \\
\hline & & Youth $(15-25$ years old $)$ \\
\hline & & Senior citizens $(65+)$ \\
\hline & & Citizens with no organizational attachment \\
\hline
\end{tabular}

\subsection{What Are the Communication Needs?}

The reported communication needs from the initial brainstorming session are listed in table 2. It is worth noticing that some of the reported needs are available today if you know what you are looking for, but these are reported to be either hard to find, of poor quality, or in a language which is not easily understood by ordinary citizens.

Table 2. Communication needs

\begin{tabular}{ll}
\hline Communication needs & Description \\
\hline Report problems & Report problems with physical infrastructure \\
\hline Information: Nature & Information about local areas for hiking and fishing \\
\hline Tourist information & Information about what happens, where to sleep and what to do \\
\hline Municipal news & News about what happens in the municipality \\
\hline Website links & Links to local web sites \\
\hline Planning information & Information on construction, road works \\
\hline $\begin{array}{l}\text { Inform on political } \\
\text { decisions }\end{array}$ & Information about decisions made by the municipal council \\
\hline Debate urban planning & Create a forum for debate \\
\hline Citizen surveys & Conduct surveys on big and important issues \\
\hline Feedback & Receive feedback from municipality after making contact \\
\hline Referral to laws & case correspondence from the municipality should include references to \\
& relevant law \\
\hline After hours contact & The municipality should be available after 4PM \\
\hline Accessible information & $\begin{array}{l}\text { Policy documents are difficult to understand, and should be made more } \\
\text { accessible to ordinary citizens. }\end{array}$ \\
\hline Geographic information & Citizens should be informed on issues in their neighbourhood. \\
\hline Rapid feedback & When contacting the municipality, receive feedback and case status. \\
\hline Comment services & Comment and provide feedback on municipal services \\
\hline
\end{tabular}


Table 2. (Continued)

\begin{tabular}{ll}
\hline Urban planning dialogue & Dialogue between business and municipality \\
\hline Information on business services & Information on services for business \\
\hline Dialogue on land use & Dialogue between business and municipality \\
\hline Dialogue on the harbour & Dialogue between business and municipality \\
\hline Dialogue on apprentice recruitment & Dialogue between business and municipality \\
\hline Dialogue with immigrants & $\begin{array}{l}\text { Establish a forum for politicians, locals and immigrants to } \\
\text { meet }\end{array}$ \\
\hline Information: geriatric & Information about plans to cope with an aging population \\
\hline Information: the church & Information about religious activities \\
\hline Information: political objectives & $\begin{array}{l}\text { Information about the long term ideas and thoughts of } \\
\text { politicians }\end{array}$ \\
\hline Information flow & $\begin{array}{l}\text { Introduce routines for information flow between } \\
\text { politicians/administration }\end{array}$ \\
\hline Discussion forum & Create a forum for discussion on long-term political issues. \\
\hline Electronic case handling & Case documents digitized for easier access \\
\hline Information: services & Inform citizens about the municipality's services. \\
\hline Information: Courses & Inform citizens about available short educational courses. \\
\hline Patient evaluation & $\begin{array}{l}\text { Patients in health care should be able to evaluate their } \\
\text { treatment }\end{array}$ \\
\hline
\end{tabular}

The 31 communication needs of the initial brainstorming were reduced to ten in the consolidation phase, and the consolidated list was presented to and approved by the participants. The ten remaining factors were grouped in the categories information dissemination, public services and public dialogue, as the qualitative data from the first phase revealed that these were the three main concerns for the participants.

Table 3. Consolidated list of communication needs, grouped by category

\begin{tabular}{lll}
\hline \multicolumn{1}{c}{ Information dissemination } & Public services & Dialogue \\
\hline Generic information & Service dialogue & Forum for debate \\
\hline Information tailored to individual needs & Evaluation of existing services & Business dialogue \\
\hline Local information & Report problems with services & Municipal surveys \\
\hline & Report problems with infrastructure & \\
\hline
\end{tabular}

Table 4 shows the communication needs that were important to the different stakeholder groups. We were not able to solicit answers from all of the civil society groups identified by our stakeholder analysis. Hence, some of the groups from table 1 are excluded from table 4 . None of the stakeholder groups ranked report problems with services as important. Tailored and local information are important to almost all of the stakeholder groups, and the qualitative data shows that these are even more important than the table suggests:

"Calling them does not work at all. It would be a lot more efficient if there was one person responsible for one area. We are located on an island where it can take one year for a light bulb to be changed, just because the right people aren't told about the problem" (Associations respondent 1).

Except for the administration, all the stakeholder groups wanted to report problems with the physical infrastructure, such as potholes, missing streetlights, poor road maintenance in winter etc. Again, this is a very important issue also in the qualitative 
data set from the brainstorming phase: "My main communication need is to comment on municipal services such as [problems with] garbage disposal and snow clearing" (Associations respondent 5).

Table 4. Stakeholder groups' communication needs

\begin{tabular}{lcccccc}
\hline & Adm. & Politicians & Seniors & Business & Youth & Associations \\
\hline Generic information & & $\mathrm{X}$ & & $\mathrm{X}$ & $\mathrm{X}$ & $\mathrm{X}$ \\
\hline Local information & $\mathrm{X}$ & $\mathrm{X}$ & $\mathrm{X}$ & & $\mathrm{X}$ & $\mathrm{X}$ \\
\hline Tailored information & $\mathrm{X}$ & $\mathrm{X}$ & $\mathrm{X}$ & $\mathrm{X}$ & $\mathrm{X}$ & $\mathrm{X}$ \\
\hline Service dialogue & $\mathrm{X}$ & $\mathrm{X}$ & & & $\mathrm{X}$ & $\mathrm{X}$ \\
\hline Evaluation of services & $\mathrm{X}$ & & & & & \\
\hline Report problems w/infrastructure & & $\mathrm{X}$ & $\mathrm{X}$ & $\mathrm{X}$ & $\mathrm{X}$ & $\mathrm{X}$ \\
\hline Forum for debate & $\mathrm{X}$ & $\mathrm{X}$ & $\mathrm{X}$ & & & $\mathrm{X}$ \\
\hline Business dialogue & $\mathrm{X}$ & $\mathrm{X}$ & $\mathrm{X}$ & $\mathrm{X}$ & & $\mathrm{X}$ \\
\hline Municipal surveys & & & & $\mathrm{X}$ & & $\mathrm{X}$ \\
\hline
\end{tabular}

Respondents were asked to pick the most important issues, and to rank them from least to most important. Table 5 shows how many of the participants who included each item in their list of most important issues. While democratic dialogue is an important issue for eParticipation, a majority of our respondents call for information tailored to individual needs, dialogue on the needs of business, a way to report problems with the physical infrastructure or information about things happening in their local area, such as planned construction and power outages. The ranking confirms these as the most important issues.

Table 5. Ranking of communication needs, all stakeholders

\begin{tabular}{ll}
\hline Communication need & Percentage \\
\hline Tailored information & $100.0 \%$ \\
\hline Business dialogue & $77 \%$ \\
\hline Report problems with physical infrastructure & $69 \%$ \\
\hline Local information & $62 \%$ \\
\hline Generic information & $46 \%$ \\
\hline Service dialogue & $46 \%$ \\
\hline Forum for debate & $31 \%$ \\
\hline Evaluation of services & $15 \%$ \\
\hline Municipal surveys & $15 \%$ \\
\hline
\end{tabular}

\subsection{How Can Practitioners Choose Media for Various Types of Communication?}

In addition to asking about the communication needs of the stakeholder groups, we also asked them which communication media they preferred to use for each category. The findings are summarized in table 6 . There were no notable differences between the stakeholder groups' preferences, so we do not report the results of the individual groups. The participants were able to choose more than one media preference for each communication need. Based on the input from the brainstorming phase, we grouped the media preferences into six categories. Four based on technology, and two physical contact points. 
Internet, as in the municipality's web site or other web sites is by far the most popular medium overall, along with e-mail whereas social media and mobile phones are less popular. Age does not seem to play an important role as the distribution between age groups is fairly similar. In terms of dialogue, social media scored higher, which is consistent with the idea of social media as a two-way medium, and an indication that governments' social media presence should include some form of feedback option. Another interesting observation is that public meetings also received a high score. This indicates that, at least in small communities, physical contact is deemed important for dialogue. Even so, the trend is clear. In most cases, some form of digital communication is the preferred option, while physical contact is still in some cases seen as important.

Table 6. Media preference for each communication category

\begin{tabular}{|c|c|c|c|c|c|c|c|c|c|}
\hline \multirow[t]{2}{*}{ Preferred medium } & \multicolumn{9}{|c|}{ Percentage for each communication need } \\
\hline & 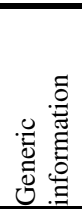 & 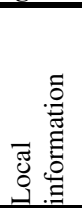 & 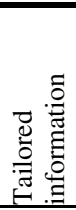 & 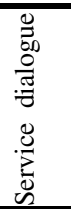 & 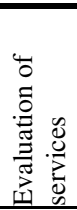 & 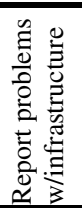 & 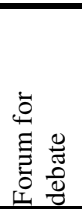 & 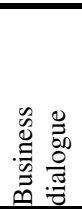 & 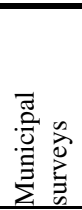 \\
\hline E-mail & 66 & 60 & 75 & 47 & 47 & 74 & 39 & 38 & 63 \\
\hline Internet & 78 & 62 & 58 & 56 & 61 & 53 & 61 & 62 & 69 \\
\hline Social media & 22 & 24 & 14 & 22 & 17 & 15 & 42 & 44 & 20 \\
\hline Mobile devices & 16 & 19 & 25 & 14 & 9 & 35 & 6 & 18 & 14 \\
\hline Service bureau & 8 & 16 & 14 & 14 & 12 & 32 & 12 & 18 & 6 \\
\hline Public meetings & 8 & 5 & 6 & 19 & 12 & 6 & 46 & 41 & 9 \\
\hline
\end{tabular}

\section{Discussion: Towards a Framework for Media Choice}

Knowing the communication needs and media preferences of the stakeholder groups in our case municipality, we are now able to move on towards the next phase, choosing the appropriate technologies for each communication need. The reported communication needs are translated into genres in our proposed framework, based on the phases from [22] and expanded with the technological framework [12].

Identify stakeholders and producers and users of information. A stakeholder analysis, such as the one presented in table 1, tells us who should participate in the communication. The next step is to identify producers and users of information (PUI entities), so that we know who should initiate and who should respond. See [22] for more on PUI entities.

Identify communication genres. For eParticipation, the first step has too often been based on the needs of government. Our identification of the communication needs of various external and internal stakeholder groups (tables 2-5), allows us to create genres that are grounded in citizen and other stakeholder needs. Identifying genres based on these communication needs can be done through the $5 \mathrm{~W} 1 \mathrm{H}$ method, as shown by [18]. Who/m is excluded from $5 \mathrm{~W} 1 \mathrm{H}$, as it is addressed in the stakeholder analysis. 
Define and gather metadata about the various genres. This should be done in collaboration with the stakeholders. Typical metadata varies depending on the type of communication, but could include preferred medium (see table 6), response time, reference number, and for government, issues such as archiving and access might also be necessary for compliance. This step overlaps with the technological analysis. These steps are shown in Table 7, with an example of a finished analysis in Table 8.

Table 7. Genre analysis

\begin{tabular}{lll}
\hline Genre : & [name] & \\
\hline Stakeholders & Producers & Who is the one producing information/ the sender \\
\hline & Users & Who is the receiver of information? \\
\hline Genre properties & Why & What is the purpose and expected outcome of the genre? \\
\hline & What & What is the information content and level of participation addressed? \\
\hline & When & $\begin{array}{l}\text { In what time-period, and where in the decision making process should } \\
\text { the genre be enacted? }\end{array}$ \\
\hline & Where & What is the reported preferred technology for the genre? \\
\hline How & $\begin{array}{l}\text { What are the technological needs, how should the genre be produced? } \\
\text { What activities are involved? }\end{array}$ \\
\hline Genre metadata & Meta 1 & Metadata is collected through user input \\
\hline Meta 2 & $\begin{array}{l}\text { Metadata can also be related to compliance issues such as archiving } \\
\text { laws }\end{array}$ \\
\hline
\end{tabular}

Table 8. Example of a genre analysis

\begin{tabular}{|c|c|c|}
\hline \multirow{2}{*}{$\begin{array}{l}\text { Genre : } \\
\text { Stakeholders }\end{array}$} & \multicolumn{2}{|c|}{ Report problems with infrastructure } \\
\hline & Producers & Citizen group members, business \\
\hline & Users & Government administration (road and transportation office) \\
\hline \multirow[t]{5}{*}{$\begin{array}{l}\text { Genre } \\
\text { properties }\end{array}$} & Why & $\begin{array}{l}\text { Report issues such as potholes, broken streetlights, so they can be fixed. } \\
\text { Expected outcomes: civic engagement }\end{array}$ \\
\hline & What & $\begin{array}{l}\text { Geographic location, type of issue, other relevant information. Level of } \\
\text { participation: collaboration }\end{array}$ \\
\hline & When & $\begin{array}{l}\text { On-going when problems are observed. Stage in decision making } \\
\text { process: Monitoring }\end{array}$ \\
\hline & Where & e-mail to municipality, internet (municipal web site), mobile \\
\hline & How & $\begin{array}{l}\text { Web-site front end where information is stored in Database. Accessible } \\
\text { through mobile app }+ \text { mobile-friendly municipal web site. Activities: } \\
\text { consultation. }\end{array}$ \\
\hline \multirow[t]{2}{*}{ metadata } & Case no & Generate case number for each report \\
\hline & Feedback & Provide feedback when problem is fixed. Linked to case number. \\
\hline
\end{tabular}

Analyse available technologies. The last step is shown in Table 9, with an example analysis in Table 10. Based on Tambouris et.al. [12], we analysed the communication media the stakeholders prefer to use for the specific genre. The technology evaluation includes the technical functionality, the level of participation and stage in decision 
making process (based on OECD recommendations) the medium can accommodate, and actors. Activities and outcomes are other important factors in eParticipation [33], and these have been added to the original technological analysis to provide a more holistic picture. While our example includes only one technology, in most cases there would probably be many suitable systems, consistent with a multichannel strategy [5].

Table 9. Technology evaluation

\begin{tabular}{l|l}
\hline Name of medium & <insert name of medium> \\
\hline Functionality & Technical functionality, such as forms, video, feedback options \\
\hline $\begin{array}{l}\text { Level of participation } \\
\begin{array}{l}\text { Stage in decision } \\
\text { making process }\end{array}\end{array}$ & $\begin{array}{l}\text { Information/two-way consultation/involvement in the political } \\
\text { process/collaboration/power transfer to citizens }\end{array}$ \\
\hline Actors & Agenda setting, Analysis, policy creation, Implementation, Monitoring \\
\hline Activities & Who has access to the technology? \\
\hline Expected outcomes & Voting, discourse form, decision making, activism, consultation, petitions \\
\hline
\end{tabular}

Table 10. Example of a finished technology evaluation table

\begin{tabular}{l|l}
\hline Name of medium & Facebook \\
\hline Functionality & $\begin{array}{l}\text { Personalised front page, Profiles, Groups, Networks, "Wall" for message } \\
\text { posting, Photo uploads, Notes/links, status updates, events, Video, Chat, 3rd } \\
\text { party applications, internal private messaging system, Search, Sharing of } \\
\text { content, Mobile app for smartphones. }\end{array}$ \\
\hline Level of participation & Information, two-way consultation collaboration \\
\hline $\begin{array}{l}\text { Stage in decision } \\
\text { making process }\end{array}$ & Agenda setting, Analysis \\
\hline Actors & $\begin{array}{l}\text { Everyone with a Facebook account. Requires participants to register, may } \\
\text { exclude privacy conscious people }\end{array}$ \\
\hline Activities & Information, activism, consultation, petitions \\
\hline Expected outcomes & Civic engagement \\
\hline
\end{tabular}

Based on tables 8 and 10, our example genre and example technology are not wellmatched if the reported metadata item "case number" is seen as very important. Using a Facebook page or group would not generate case numbers, does not allow reported cases to be stored in a database, and privacy issues related to ownership of data could also be an obstacle for this particular genre. This short example shows the importance of addressing both the technology and the users' preferences for communication before starting on an eParticipation project, and we believe our framework could serve as a guide in this sense.

\section{$6 \quad$ Limitations and Future Research}

While this study provides insights into the communication needs and media preferences of various stakeholder groups, there are some limitations that need to be addressed. As we were not able to reach consensus in the Delphi study, we were unable to create a definite list of communication needs to be addressed. However, we were still able to identify some needs, and through the survey that was distributed 
later, we also got data to verify the findings from the Delphi study. Our findings should however be read mainly as qualitative and interpretive, and within the contextual limitations of a small Norwegian municipality, rather than quantitative.

Our combination of the eParticipation technology framework and genre frameworks is mainly based on theory and inspired by the findings on communication preferences. A logical next step in this research would be to verify the framework through testing it in government. Specifically, validation of a common list of communication needs and the appropriate technology to support each communication need is considered to be an important contribution to further practical development.

\section{References}

1. Kitchin, R.: Cyberspace: The world in the wires. John Wiley \& Sons, Chichester (1998)

2. Kjensli, H., et al.: eKommune 2012: Lokal digital agenda. Oslo, Kommuneforlaget AS (2008)

3. Mazzoleni, G., Schulz, W.: "Mediatization" of politics: A challenge for democracy? Political Communication 16(3), 247-261 (1999)

4. Gurevitch, M., Coleman, S., Blumler, J.G.: Political communication -old and new media relationships. Annals of the American Academy of Political and Social Science 625(1), 164-181 (2009)

5. Ebbers, W.E., Pieterson, W.J., Noordman, H.N.: Electronic government: Rethinking channel management strategies. Government Information Quarterly 25(2), 181-201 (2008)

6. Gastil, J., Dillard, J.P.: Increasing political sophistication through public deliberation. Political Communication 16(1), 3-23 (1999)

7. Davis, A.: New media and fat democracy: The paradox of online participation. New Media and Society 12(5), 745-761 (2010)

8. Carr, D.S., Halvorsen, K.: An Evaluation of Three Democratic, Community-Based Approaches to Citizen Participation: Surveys, Conversations With Community Groups, and Community Dinners. Society \& Natural Resources 14(2), 107-126 (2001)

9. Rayner, S.: Democracy in the age of assessment: Reflections on the roles of expertise and democracy in public-sector decision making. Science and Public Policy 30(3), 163-170 (2003)

10. Jackson, N.A., Lilleker, D.G.: Building an Architecture of Participation? Political Parties and Web 2.0 in Britain. Journal of Information Technology and Politics 6(3), 232-250 (2009)

11. Johannessen, M.R., Munkvold, B.E.: Defining the IT Artefact in Social Media for eParticipation: An emsemble view. In: European Conference on Information Systems, ECIS, Barcelona (2012)

12. Tambouris, E., Liotas, N., Tarabanis, K.: A Framework for Assessing eParticipation Projects and Tools. In: Hawaii International Conference on System Sciences, Hawaii (2007)

13. Rose, J., Sæbø, Ø.: Designing Deliberation Systems. The Information Society 26(3), 228240 (2010)

14. Yates, J., Orlikowski, W.J.: Genres of Organizational Communication: A Structurational Approach to Studying Communication and Media. The Academy of Management Review 17(2), 299-326 (1992) 
15. Orlikowski, W.J., Yates, J.: Genre Repetoire: The Structuring of Communicative Practices in Organizations. Administrative Science Quarterly 39(4), 541-574 (1994)

16. Shepherd, M., Watters, C.: The evolution of cybergenres. In: Proceedings of the ThirtyFirst Hawaii International Conference on System Sciences (1998)

17. Yates, J., Orlikowski, W.: Genre Systems: Structuring Interaction through Communicative Norms. Journal of Business Communication 39(1), 13-35 (2002)

18. Päivärinta, T., Sæbø, Ø.: The Genre System Lens on E-Democracy. Scandinavian Journal of Information Systems 20(2) (2008)

19. Sæbø, Ø., Flak, L.S., Sein, M.K.: Understanding the dynamics in e-Participation initiatives: Looking through the genre and stakeholder lenses. Government Information Quarterly 28(3), 416-425 (2011)

20. Sæbø, Ø.: Understanding twitter ${ }^{T M}$ use among parliament representatives: A genre analysis. In: Tambouris, E., Macintosh, A., de Bruijn, H. (eds.) ePart 2011. LNCS, vol. 6847, pp. 1-12. Springer, Heidelberg (2011)

21. Rose, J., Sæbø, Ø.: Democracy Squared: designing on-line political communities to accommodate conflicting interests (2005)

22. Päivärinta, T., Halttunen, V., Tyrväinen, P.: A Genre-Based Method for Information Systems Planning. In: Rossi, M., Siau, K. (eds.) Information Modeling in the New Millenium, pp. 70-93. Idea Group Publishing, Hershey (2001)

23. Haraldsen, M., et al.: Developing e-Government Portals: From Life-Events through Genres to Requirements. In: The 11th Norwegian Conference on Information Systems (NOKOBIT), Stavanger, Norway (2004)

24. Mingers, J.: Combining IS Research Methods: Towards a Pluralist Methodology. Info. Sys. Research 12(3), 240-259 (2001)

25. Freeman, R.E.: Strategic Management. A Stakeholder Approach. Pitman, Boston (1984)

26. Flak, L.S., Rose, J.: Stakeholder Governance: Adapting Stakeholder Theory to the eGovernment Field. Communications of the Association for Information Systems 16, 642664 (2005)

27. Scholl, H.J.: Involving Salient Stakeholders. Action Research 2(3) (2004)

28. Okoli, C., Pawlowski, S.D.: The Delphi method as a research tool: an example, design considerations and applications. Information and Management 42(1), 15-29 (2004)

29. Schmidt, R.C.: Managing Delphi Surveys Using Nonparametric Statistical Techniques. Decision Sciences 28(3), 763-774 (1997)

30. Rayens, M.K., Hahn, E.J.: Building Consensus Using the Policy Delphi Method. Policy, Politics \& Nursing Practice 1(4), 308-315 (2000)

31. Päivärinta, T., Dertz, W.: Pre-determinants of Implementing IT Benefits Management in Norwegian Municipalities: Cultivate the Context. In: Wimmer, M.A., Scholl, H.J., Ferro, E. (eds.) EGOV 2008. LNCS, vol. 5184, pp. 111-123. Springer, Heidelberg (2008)

32. Grönlund, Å., Ranerup, A.: Elektronisk förvaltning, elektronisk demokrati: visioner, verklighet, vidareutveckling. Studentlitteratur, Lund (2001)

33. Sæbø, Ø., Rose, J., Skiftenes Flak, L.: The shape of eParticipation: Characterizing an emerging research area. Government Information Quarterly 25(3), 400-428 (2008) 